\title{
Chromosome Number Instability in Phalaris L.
}

\author{
Maria Teresa Schifino, Carla C. Zanella and Rejane Gus \\ Setor de Plantas Forrageiras, Departamento de Fitotecnia, Faculdade \\ de Agronomia, Universidade Federal do Rio Grande do Sul, Caixa \\ Postal 776, 90000 Porto Alegre, RS, Brazil
}

Accepted August 12, 1983

Of the 15 species belonging to the genus Phalaris L., two are of special interest to plant breeders: $P$. aquatica L. (syn. $P$. tuberosa L.) ${ }^{1}$ and $P$. arundinacea L., vigorous perennial grasses in temperate zones, presently cultivated in several parts of the world (Bogdan 1977). Natural and artificial hybrids between these two species are known, including a successful allopolyploid hybrid (Covas and Cialzeta 1953). The palatability of $P$. aquatica is much better than that of $P$. arundinacea or their hybrids; toxic substances harmful to cattle may also be present in the two species and their hybrids (Bogdan 1977).

Several interesting cytogenetic investigations have been performed on these species. Euploid chromosome numbers of $P$. aquatica are reported as $2 \mathrm{n}=14$ or 28 and those of $P$. arundinacea as $2 \mathrm{n}=14,28,35$ and 42, aneuploidy being referred in $P$. arundinacea and hybrids. Meiosis seems to be mainly regular in the two species except in pentaploid $(2 \mathrm{n}=35) P$. arundinacea, its progenies, progenies from different $P$. aquatica ecotypes and hybrids between the two species (Jenkin and Sethi 1932, Parthasarathy 1939, Myers 1947, Hanson and Hill 1953, Love and Mohrdieck 1955, Ambastha 1956, Carnahan and Hill 1956, Starling 1961, Federov 1969, Putievsky et al. 1980).

From 1968 to 1969106 introductions of Phalaris, probably all $P$. aquatica and $P$. arundinacea, were brought to Rio Grande do Sul. The correct identification of most of these introductions is presently unknown. The plants were grown in lines and periodically cut. But natural hybridization in the field and mixture of lines could have occurred. Of these 106 introductions, 15 were selected and evaluated (Kohmann et al. 1980). Afterwards, two groups of 40 and 39 plants, respectively, were selected. Besides differences in overall morphology, the first group had higher forage production, lower palatability and generally higher alkaloid content (Kohmann, personal communication). The present paper describes a cytogenetic investigation of these plants, aiming at characterizing each individual, to detect possible chromosomal differences between the two groups, and to verify the presence of hybrids.

1 According to B. Rosengurtt (personal communication) the term P. stenoptera Hackel should be used instead of $P$. aquatica, since it seems that all South American cultivated material came from Australia, the region of Hackel's typus, while P. aquatica L. is European. However, in this paper we are also going to use the name $P$. aquatica, since most of the authors we cite do so. 


\section{Material and methods}

Cuttings of the 79 plants were brought from the Experimental Station at Vacaria, RS, Brazil, and grown in two plots at our Unit. Part of the adult plant or at least the inflorescences were then herborized and kept as vouchers. Unfortunately it was not possible to get a sample of every plant examined. Taxonomic identification of the herborized material was kindly performed by Dr. B. Rosengurtt, Universidad de Montevideo. However, as Dr. Rosengurtt pointed out (personal communication) in some cases the material was too young to permit a precise classification.

For pollen mother cells (PMC) analysis young inflorescences were fixed in $3: 1$ ethanol-acetic acid for 12 to 24 hours and stored in $70 \%$ alcohol in the refrigerator until study. Slides were prepared by squashing the anthers in propionic carmine. The meiotic index (number of normal tetrads/total number of tetrads $\times 100$ ) was calculated from at least two inflorescences per plant. Tetrads were considered normal if they did not show micronuclei, cell wall defects or asynchronous division, and had four microspores. The percentage of normal microspores (number of normal microspores/total number of microspores observed $\times 100$ ) was also determined. Normal microspores were defined as those without micronuclei or other abnormalities; those coming from "triads" or "polyads" were always regarded as abnormal.

For root-tip somatic chromosome number determinations tillers were removed from the adult plants, their leaves and old roots were cut, and they were then grown in little pots with very humid soil for a week, until good rooting was achieved. The young roots were excised, pretreated in a saturated solution of paradichlorobenzene for 18 to 20 hours at $4^{\circ} \mathrm{C}$, fixed in $3: 1$ ethanol-acetic acid for 12 to 24 hours, and stored in $70 \%$ alcohol in the refrigerator until study. For slide preparation the roots were washed in distilled water, treated in a $5 \%$ pectinase solution for 1 hour, hydrolyzed in $5 \mathrm{~N} \mathrm{HCl}$ for 1 hour, stained in acetic-carmine for 1 day and squashed in the same stain.

\section{Results}

Tables 1 and 2 summarize the results. Plants numbered from 1 to 40 are those of the "first group" and those numbered 41 to 79 will be referred as the "second group". The taxonomic determination of available vouchers showed that plants of the first group were mainly $P$. arundinacea, with at least one individual (no. 4) showing characteristics of both species. All those of the second group which could be classified were $P$. aquatica. During the cultivation in plots plants of the first group showed dark green leaves and flowered later (most plants in December) while those of the second group had light green leaves and were earlier flowering (most plants in November).

As is shown in Table 2 all the second-group plants had $2 n=28$ chromosomes (except no. 41), forming mainly 14 bivalents at diakinesis and metaphase I (Figs. $1, \mathrm{a}, \mathrm{b}$ ), eventually some multivalents (Fig. 1, c) and having regular disjunction at 


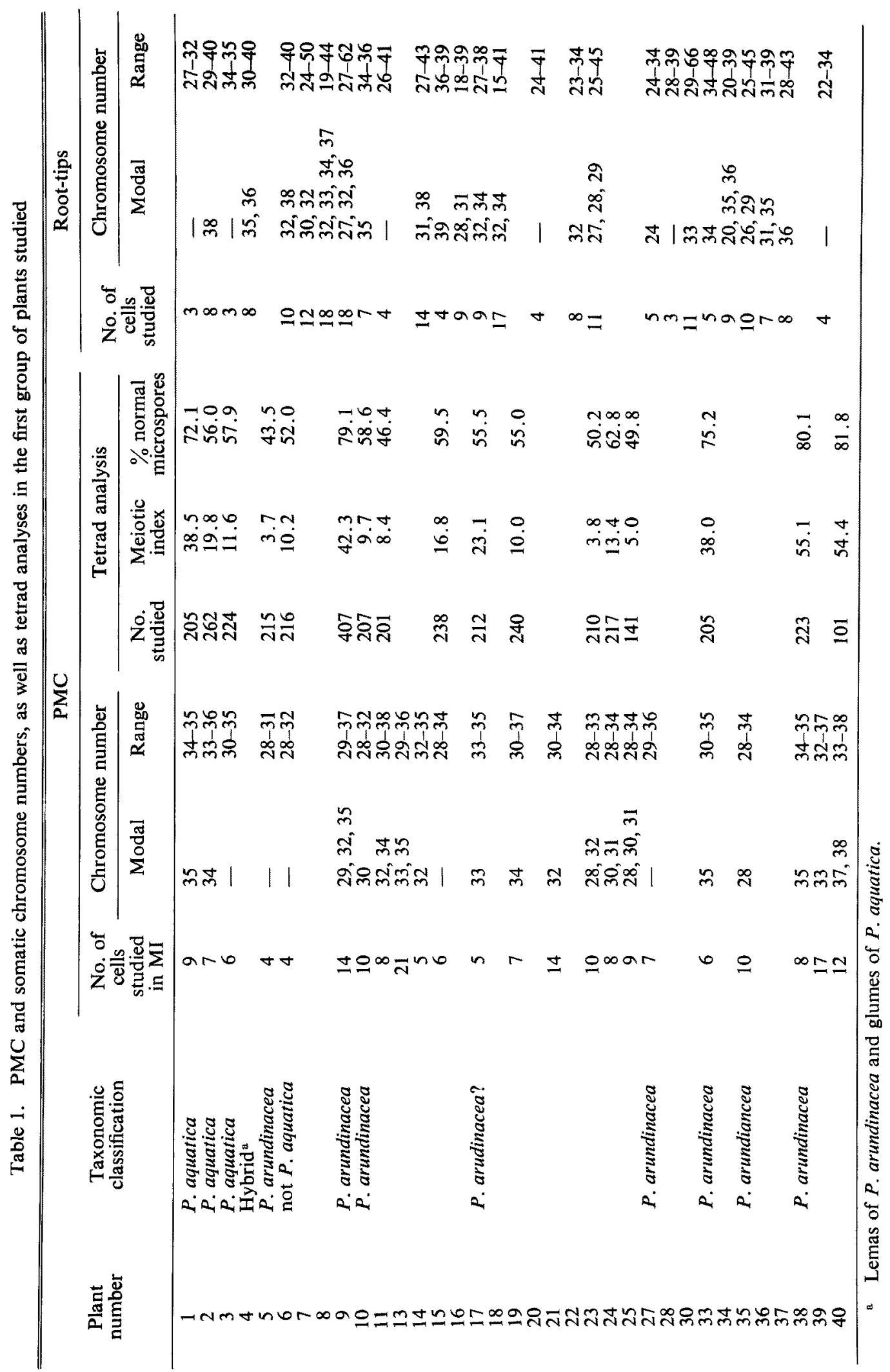


anaphase I (Fig. 1, d). Secondary associations of chromatin-like thin threads were occasionally seen between bivalents (Figs. 1, b, c). Plant number 72 presented 1 to 3 quadrivalents (Fig. 1, e) in its PMC at diakinesis, and even higher associations have been observed. Plant 41 showed some variation in PMC chromosome number (28 to 32 , the mode being 28 ). The meiotic index ranged from $76.4 \%$ (plant 46 ) to

Table 2. PMC and somatic chromosome numbers, as well as tetrad analyses in the second group of plants studied

\begin{tabular}{|c|c|c|c|c|c|c|}
\hline \multirow{3}{*}{$\begin{array}{l}\text { Plant } \\
\text { number }\end{array}$} & \multirow{3}{*}{$\begin{array}{l}\text { Taxonomic } \\
\text { classification }\end{array}$} & \multicolumn{5}{|c|}{ PMC } \\
\hline & & \multirow{2}{*}{$\begin{array}{l}\text { No. of } \\
\text { cells } \\
\text { studied } \\
\text { in MI }\end{array}$} & \multirow{2}{*}{$\begin{array}{l}\text { Chromosome } \\
\text { number }\end{array}$} & \multicolumn{3}{|c|}{ Tetrad analysis } \\
\hline & & & & $\begin{array}{c}\text { No. } \\
\text { studied }\end{array}$ & $\begin{array}{c}\text { Meiotic } \\
\text { index }\end{array}$ & $\begin{array}{c}\% \text { normal } \\
\text { micorspores }\end{array}$ \\
\hline $41^{a}$ & P. aquatica & 24 & 28 & 201 & 86.6 & 95.6 \\
\hline 42 & P. aquatica & 32 & 28 & 200 & 96.0 & 98.9 \\
\hline 43 & & 16 & 28 & 204 & 97.0 & 99.1 \\
\hline 44 & P. aquatica & 11 & 28 & & & \\
\hline 45 & & 14 & 28 & 200 & 96.0 & 98.4 \\
\hline 46 & & 24 & 28 & 212 & 76.4 & 92.7 \\
\hline 47 & & 31 & 28 & & & \\
\hline 50 & & 12 & 28 & 200 & 97.5 & 98.6 \\
\hline 51 & P. aquatica & 24 & 28 & 200 & 98.0 & 99.2 \\
\hline 52 & & 19 & 28 & 200 & 99.5 & 99.9 \\
\hline 53 & & 10 & 28 & 175 & 97.7 & 99.4 \\
\hline 55 & & 25 & 28 & 200 & 96.5 & 98.6 \\
\hline 56 & & 18 & 28 & 206 & 93.2 & 97.7 \\
\hline 57 & & 17 & 28 & 202 & 91.6 & 97.0 \\
\hline 59 & & 26 & 28 & 200 & 98.0 & 99.4 \\
\hline 60 & P. aquatica & 10 & 28 & 204 & 95.6 & 98.9 \\
\hline 67 & & 51 & 28 & & & \\
\hline 69 & $P$. aquatica & 12 & 28 & 204 & 98.0 & 99.4 \\
\hline 71 & & 65 & 28 & & & \\
\hline 72 & $P$. aquatica & 40 & 28 & 202 & 87.1 & 93.5 \\
\hline 73 & P. aquatica & 28 & 28 & & & \\
\hline 74 & P. aquatica & 32 & 28 & 200 & 99.5 & 99.7 \\
\hline 75 & $P$. aquatica & 33 & 28 & & & \\
\hline 79 & $P$. aquatica & 18 & 28 & 111 & 93.7 & 98.4 \\
\hline
\end{tabular}

a This was the only plant in which a variation of chromosome number was seen in PMC (modal no.: 28; range: $28-32$ ). Twenty root-tip cells were examined. There the modal number was 31 , with a range of $10-44$.

Fig. 1. $a$ and b, diakinesis with 14 II and secondary bivalent association (arrow). c, diakinesis, 12II, 1IV, secondary association of bivalents (arrow). d, anaphase I, 14/14 disjunction. e, plant number 72, diakinesis, 8II, 3IV. f, metaphase I showing clumping of chromosomes and several univalents. $\mathrm{g}$, diakinesis of difficult interpretation but certainly showing multiple associations. $\mathrm{h}$, anaphase I, 35 chromosomes. $\mathrm{i}$ and $\mathrm{j}$, anaphase $\mathrm{I}$ with bridges and laggards. $\mathrm{k}$, anaphase I with a dividing univalent (arrow). 1, anaphase I with one undivided bivalent (arrow). m, dyad (interkinesis) with micronuclei. $\mathrm{n}$, dyad with bridges. o, metaphase II showing divided chromatids (arrows). p, tetrad with several micronuclei. q, tetrad with a laggard being trapped by the wall formation. $r$, microspore prior to pollen wall formation presenting two micronuclei. $s$,

"giant" pollen grain, presumably originated from an undivided tetrad. Scale $=10 \mu \mathrm{m}$. 


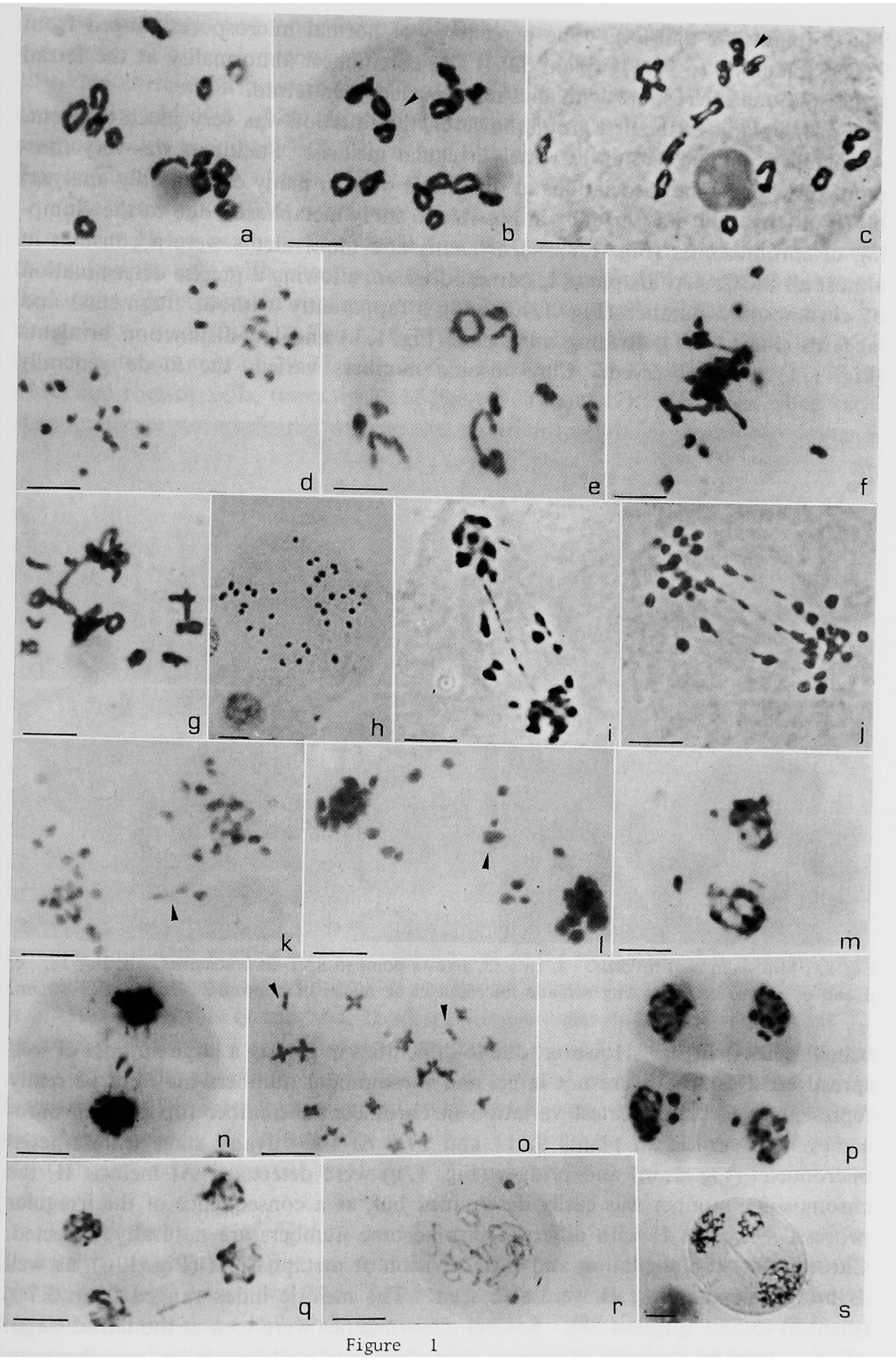


99.5\% (plants 52 and 74). The percentage of normal microspores ranged from $92.7 \%$ (plant 46 ) to $99.9 \%$ (plant 52 ). The commonest abnormality at the tetrad stage was one microspore with one micronucleus per tetrad.

For the plants of the first group, however, the situation was very much different. All plants examined had an extremely irregular meiosis. Stickiness was very common. Chromosome associations at diakinesis were in many cases hardly analyzable (Fig. 1, g) and it was virtually impossible to study metaphase I due to the clumping of chromosomes (Fig. 1,f). Univalents and multivalents were a constant in almost all PMC. At anaphase I, normal division, allowing a precise determination of chromosome number (Fig. 1, h), bridges (apparently without fragments) and laggards (Figs. 1, i, f), dividing univalents (Fig. 1, k) and late-disjunction bivalents (Fig. 1,1) were observed. Chromosome numbers varied, the mode generally

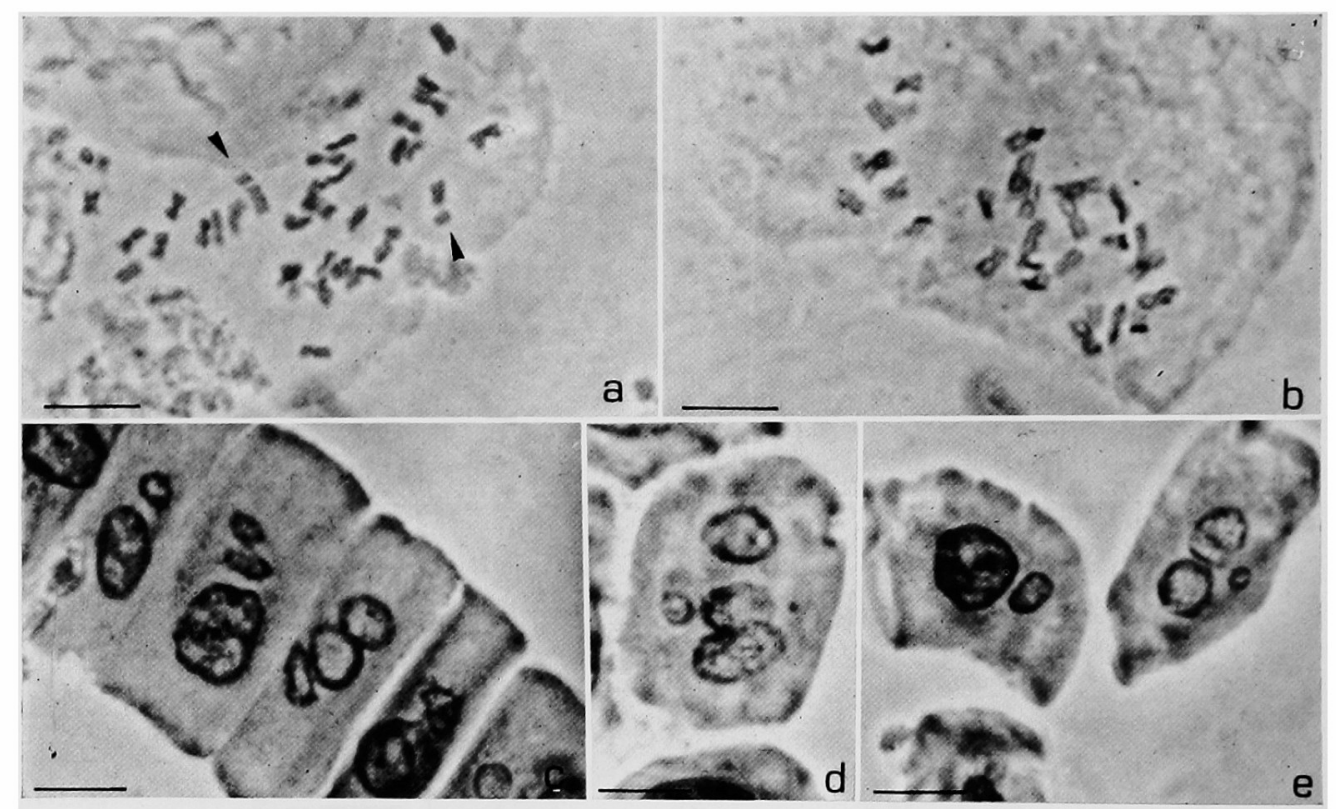

Fig. 2. Mitosis in root-tip cells. a, $2 n=35$, arrows point to SAT-chromosomes. b, $2 n=28$. c, $\mathrm{d}$ and e, several cells showing somatic micronuclei or nuclei of abnormal size. Scale $=10 \mu \mathrm{m}$.

being higher than 30 . However, due to difficulties in getting a large number of well spread cells, samples were not large, and these modal numbers may not be really representative. The greatest variation in chromosome number (up to 8 chromosomes) was verified in plants 9,11 and 27. At the "dyad" stage (interkinesis) micronuclei (Fig. 1, m) and bridges (Fig. 1, n) were detected. At meiosis II, the chromosome number was easily determined but, as a consequence of the irregular process, meiocytes II with different chromosome numbers are naturally expected. Chromosome fragmentation and early division at metaphase II (Fig. 1, o), as well as bridges at anaphase II were also seen. The meiotic index ranged from $3.7 \%$ (plant 5) to $55.1 \%$ (plant 38 ). Several abnormalities were seen at the tetrad stage: one to several micronuclei of various sizes, defects of wall formation, asynchronous division, chromosome bridges, "triads", "polyads", etc. (Figs. 1, p, q). The com- 
monest abnormality was noe microspore with one micronucleus per tetrad. The percentage of normal microspores ranged from $43.5 \%$ (plant 5 ) to $81.8 \%$ (plant 40). No correlation between meiotic indices and variation in PMC chromosomes could be established. The observed abnormalities gave rise to differentiated microspores with micronuclei (Fig. 1,r) and although infrequently, to "giant" pollen grains (Fig. 1, s).

The variation in PMC chromosome numbers in the first group of plants and in number 41 led us to study root-tip somatic chromosomes. To avoid technical errors, just the cells with intact walls and little superposition of chromosomes were analyzed. Differences in chromosome number among cells of the same root-tip were also verified (Table 1, Figs, 2, a, b) being generally higher than those in PMC (for instance, ranges of $29-37$ and $27-62 ; 30-38$ and $26-41 ; 33-35$ and $27-38$ in PMC and root-tip cells, respectively, of plants 9,11 and 17). The cases when variation in the root-tip cells did not include variation in PMC (for example, plants 3 and 39) or the ranges did not even overlap (e. g. plants 1, 10 and 15) may be easily understood considering the restricted sample sizes. The same reasoning applies to the modal chromosome numbers in root-tip cells, as compared to PMC. Several mitotic disturbances, as bridges, laggards, multipolar mitosis and micronuclei or "extranuclei" (Figs. 2, c, d, e) were also seen.

\section{Discussion}

Meiotic behavior in tetraploid $P$. aquatica has been reported as mainly regular, with 14 bivalents at diakinesis and metaphase I, a low frequency of uni- and multivalents and eventually secondary associations between bivalents, that could indicate terminal homology or association of heterochromatic regions (Jenkin and Sethi 1932, Ambastha 1956, Starling 1961). Our data for the second-group plants are in agreement with these results. On the other hand, it has been reported that hybrids between different ecotypes of $P$. aquatica presented several meiotic abnormalities. The presence of bivalents in a dihaploid which originated from $2 n=28$ parental lines with regular meiotic behavior led to the suggestion that this species is a segmental allotetraploid with genetic control of homoeologous pairing (Putievsky et al. 1980). In this connection, the interesting meiotic behavior of our plant 72 (that presented 1 to 3 quadrivalents-see Fig. 1, e-and even higher associations in all its PMCs) should be emphasized. This could be explained by assuming heterozygosity for at least three interchanges, but the associations could also reflect homology between the constituent genomes, supporting the segmental allotetraploid origin, and/or a partial breakdown of the controlling system of homeologous pairing.

Meiotic behavior of Phalaris arundinacea $(2 n=28)$ has also been described as predominantly regular. But univalents, multivalents, stickiness between bivalents and laggards also occur, and $2 n=35$ plants presented several univalents (Jenkin and Sethi 1932, Hanson and Hill 1953, Carnahan and Hill 1956, Starling 1961). Hybrids between tetraploid $P$. aquatica and $P$. arundinacea displayed a high number of bivalents, but also several abnormalities as multivalents, univalents, clumping of the 
chromosomes in the equatorial plate at metaphase I, bridges at anaphase I and II, laggards, and a high proportion of pollen quartets with micronuclei (Jenkin and Sethi 1932, Covas and Cialzeta 1953, Ambastha 1956, Starling 1961). Our observations on the meiotic behavior of the first-group plants fit well to these data on hybrids. Similar meiotic irregularities were found, for instance, in hybrids between Lolium multiflourm and Festuca arundinacea (Springer and Buckner 1982).

Aneuploidy was found in $P$. arundinacea, as well as variation from $2 \mathrm{n}=28$ to $2 n=56$ in progenies of natural $(2 n=35)$ pentaploids (Hanson and Hill 1953, Carnahan and Hill 1956). In the hybrid progenies between $P$. aquatica and $P$. arundinacea chromosome numbers of $28,34,36,42$ to 44 and 56 hvae been reported (Ambastha 1956, Love and Mohrdieck 1955), as well as PMC eventually differing in ploidy level in colchicine induced amphiploids (Starling 1961). However, the great variation we found in the number of chromosomes in PMC and especially in somatic root-tip cells had not yet been described for Phalaris.

Constancy in somatic chromosome number is expected in most species despite the well known cases, most common in plants, of aneuploidy and polyploidy. In Claytonia virginica there is even a seasonal variation in the chromosome constitution of the population (Lewis 1970, Lewis and Oliver 1971). At least in the same individual one expects somatic chromosome number to be constant (not considering B chromosomes), but polyploid cells may normally occur in dliploid tissues of plants and animals; while aneuploidy is very frequent in plant and animal tissues, cell cultures (see, for instance, Bayliss 1975) and tumors. Somatic reduction, i.e. reduction of chromosome number in non-meiotic tissues may be spontaneous or induced in some plants and animals (Schulz-Schaeffer 1980). It is a natural ontogenetic process in cycad apogeotropic roots (Storey 1968), may be artificially induced in Allium cepa (Huskins 1948b, Huskins and Cheng 1950), Sorghum (Chen and Ross 1963) or may appear due to environmental conditions in Lotus glacialis (Fernandes and Queiros 1980). Variations in somatic chromosome number among cells of the same root-tip occur in Poa pratensis (Miroshnichenko and Avrasina 1975), Poa alpina (Müntzing 1980) and Triticum aestivum (Guerra Filho and Moraes Fernandes 1977). PMCs lacking entire chromosome complements were seen in Agrostis, Potentilla and Triticum (Carlbom 1969). In Hymenocallis calathinum the variation among root-tip cells $(2 n=23$ to $2 n=83)$ was much larger than that among PMC (69 to 86 chromosomes), suggesting different levels of tolerance to chromosome instability in anthers and roots (Snoad 1955), what is in general agreement with our data. It seems that somatic reduction, variation in ploidy level or aneuploidy among cells of the same individual is most common in hybrids or induced amphiploids. Examples are the somatic cells of progenies of the induced octoploid of Medicago sativa (Sadasivaiah and Lesins 1974), Rubus hybrids (Britton and Hull 1957) and PMCs of new amphiploids of Triticum, Aegilops and Agropyron (Sachs 1952, who also cites several other examples in hybrids).

It could be argued that the pretreatment may have caused the root-tip abnormalities reported here, but other authors, analyzing treated and untreated material, concluded that the pretreatment do not cause, only enhancing a process that occurs naturally (Huskins 1948a, b, Guerra Filho and Moraes Fernandes 1977). More- 
over, the pretreatment we used is routinely employed in our laboratory and no such abnormalities were seen in other material.

Concluding, if we consider a) the irregular meiotic behavior; b) the chromosome number variation; c) the existence of at least one plant with morphological characteristics of both species; and d) the well-known fact that, in some crosses, the progeny individuals may resemble much more one of the parents, the hypothesis that most of the first-group plants (and number 41?) are of hybrid origin appears highly likely. It is interesting to notice that these plants are giving a higher forage yield than the unmixed strains of $P$. aquatica. Points for further investigation are the relationship of hybridity (or of specific chromosomes) with the somatic instability, degree of palatability, alkaloid content and flowering time.

\section{Acknowledgements}

We are indebted to Eng. Agr. Carlos Kohmann, Secretaria de Agricultura do Estado do Rio Grande do Sul, for supplying the plants, to Dr. Bernardo Rosengurtt, Universidad de Montevideo, for taxonomic advice, and to Dr. Brian G. Murray, University of Auckland for valuable suggestions. We are especially grateful to Dr. Francisco M. Salzano, Universidade Federal do Rio Grande do Sul, for critically reading and correcting the manuscript. This research was supported by the Fundação de Amparo à Pesquisa do Estado do Rio Grande do Sul, Convênio FINEP/Forrageiras, Pró-Reitoria de Pesquisa e Pós-Graduação da Universidade Federal do Rio Grande do Sul, and Conselho Nacional de Desenvolvimento Científico e Tecnológico (Programa Integrado de Genética).

\section{Summary}

Chromosome numbers and meiotic behavior were studied in two groups of plants selected in a breeding programme of Phalaris, which differed in forage yield, degree of palatability, alkaloid content and flowering time. One of them, with most if not all plants of $P$. aquatica, had $2 \mathrm{n}=28$ chromosomes and a mainly regular meiosis, the meiotic index ranging from $76.4 \%$ to $99.5 \%$. The other, with individuals resembling $P$. aquatica, $P$. arundinacea and intermediates between the two, had extremely irregular meiotic behavior (univalents, bivalents, stickiness, bridges, laggards, micronuclei), the meiotic index varying from $3.7 \%$ to $55.1 \%$. The PMC chromosome number ranged from $2 n=28$ to $2 n=38$. A larger variation in root-tip chromosomes $(2 n=15-66)$ as well as evidences of somatic mosaicism were also verified. The hybrid origin of these chromosomally unstable plants was suggested. Chromosome aberrations and aneuploidy have been previously described in these species and their hybrids, but not in such an extreme degree.

\section{References}

Ambastha, H. N. S. 1956. Cytological investigations in Phalaris. Genetica 28: 64-98.

Bayliss, H.W. 1975. The effects of growth in vitro on the chromosome complement of Daucus 
carota (L.) suspension cultures. Chromosoma 51: 401-411.

Bogdan, A. V. 1977. Tropical Pasture and Fodder Plants. Longman, London.

Britton, D. M. and Hull, J. W. 1957. Mitotic instability in Rubus. J. Hered. 48: 11-20.

Carlbom, C. 1969 . Premeiotic reduction in Agrostis L., Potentilla L. and Triticum L. Hereditas 61: $421-423$.

Carnahan, H. L. and Hill, H. D. 1956. Cytogenetic of progenies of 35-chromosome reed canarygrass (Phalaris arundinacea L.) Agron. J. 48: 356-359.

Chen, C. H. and Ross, J. G. 1963. Colchicine induced somatic reduction in Sorghum. I. Induction of diploid plants from tetraploid seedlings. J. Hered. 54: 96-100.

Covas, G. and Cialzeta, C. 1953. Alopoliploide sintético del género Phalaris, de posible valor económico como planta forrageira. Boletim do IDIA 62: 8-10.

Federov, AN. A. 1969. Chromosome Numbers of Flowering Plants. Academy of Sciences of the USSR, Moscow.

Fernandes, A. and Queiros, M. 1980. Sur l'occurrence de la pseudoinduction somatique chez Lotus glacialis. Bol. Soc. Brot. 54: 133-152.

Guerra Filho, M. S. and Moraes Fernandes, M. I. B. 1977. Somatic instability in the Brazilian semi-dwarf wheat IAS 54. Can. J. Genet. Cytol. 19: 225-230.

Hanson, A. A. and Hill, H. D. 1953. The occurrence of aneuploidy in Phalaris spp. Bull. Torr. Bot. Club 80: $16-20$.

Huskins, C. L. 1948a. Chromosome multiplication and reduction in somatic tissues. Nature 161: 80-83.

- 1948b. Segregation and reduction in somatic tissues. I. Initial observations of Allium cepa. J. Hered. 39: 311-325.

- and Cheng, K. C. 1950. Segregation and reduction in somatic tissues. IV. Reductional groupings induced in Allium cepa by low temperature. J. Hered. 41: 13-18.

Jenkin, T. J. and Sethi, B. L. 1932. Phalaris arundinacea, Ph. tuberosa, their $F_{1}$ hybrids and hybrid derivatives. J. Gen. 26: 1-36.

Kohmann, C., Bassols, P. A., Schell da Silva, V.P., Nabinger, C., Paim, N. R., Saibro, J. C., Costanzi, A. R., Calliiari, A. R. and Soares, H. H. P. R. F. 1980. Avaliação de quinze introduçeõs de faláris (Phalaris sp). Anu. Téc. do IPZFO 8: 317-369.

Lewis, W. H. 1970. Chromosomal drift, a new phenomenon in plants. Science 168: 1115-1116.

- and Oliver, R. L. 1971. Meiotic chromosomal variation in Claytonia virginica. J. Hered. 62: 379-380.

Love, R. M. and Mohrdieck, K. H. 1955. Citogenética de um híbrido natural Phalaris arundinacea L. $\times$ Phalaris tuberosa var. stenoptera (Hack). Hitchc. Bol. Diret. Prod. Animal 22: $42-44$.

Miroshnichenko, E. YA. and Avrasina, I. V. 1975. Karyological polymorphism of Siberian biotypes of Kentucky bluegrass Poa pratensis L. Genetika 11 : 45-49.

Müntzing, A. 1980. Mode of propagation and chromosomal peculiarities in Scotch material of Poa alpina. Hereditas 92: 291-296.

Myers, W. M. 1947. Cytology and genetics of forage grasses. Bot. Rev. 13: 319-421.

Parthasarathy, N. 1939. Cytogenetical studies in Oryzeae and Phalarideae. III. Cytological studies in Phalarideae. Ann. Bot. N.S. 3: 43-76.

Putievsky, E., Oram, R. N. and Malafant, K. 1980. Chromosomal differentiation among ecotypes of Phalaris aquatica L. Aust. J. Bot. 28: 645-657.

Sachs, L. 1952. Chromosome mosaics in experimental amphiploids in the Triticineae. Heredity 6: $157-160$.

Sadasivaiah, R. S. and Lesins, K. 1974. Reduction of chromosome number in root-tip cells of Medicago. Can. J. Genet. Cytol. 16: 219-227.

Schulz-Schaeffer, J. 1980. Cytogenetics. Plants, Animals, Humans. Springer-Verlag, New York.

Snoad, B. 1955. Somatic instability of chromosome number in Hymenocallis calathinum. Heredity 9: 129-134.

Springer, W. D. and Buckner, R. C. 1982. A meiotic examination of Lolium multiflorum Lam. $\times$ 
Festuca arundinacea Schreb. $F_{1}$ hybrids. Crop Science 22: 305-309.

Starling, J. L. 1961. Cytogenetic study of interspecific hybrids between Phalaris arundinacea and P. tuberosa. Crop Science 1: 107-111.

Storey, W. B. 1968 . Somatic reduction in cycads. Science 159: 648-650. 